
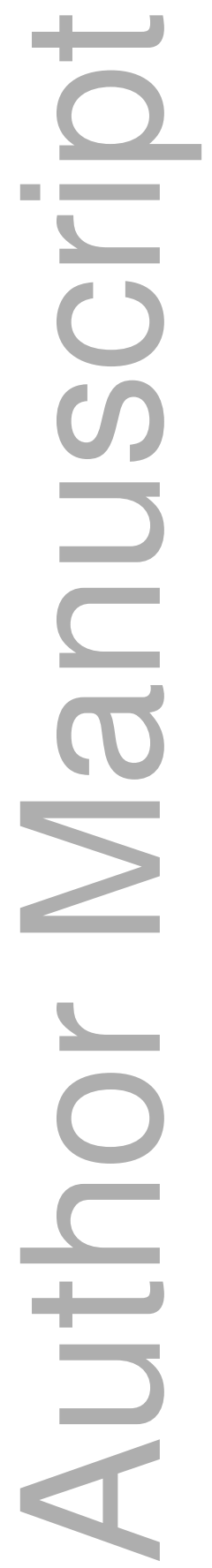

This is the author manuscript accepted for publication and has undergone full peer review but has not been through the copyediting, typesetting, pagination and proofreading process, which may lead to differences between this version and the Version of Record. Please cite this article as doi: $\underline{10.1111 / \text { nph.16420 }}$

This article is protected by copyright. All rights reserved 


\section{Related plants tend to share pollinators and herbivores, but strength of phylogenetic signal varies among plant families}

Alyssa R. Cirtwill ${ }^{\dagger 1,2}$, Giulio V. Dalla Riva ${ }^{3}$, Nick J. Baker ${ }^{1}$, Mikael Ohlsson ${ }^{4}$, Isabelle Norström ${ }^{4}$, Inger-Marie Wohlfarth ${ }^{4}$, Joshua A. Thia ${ }^{1}$, \& Daniel B. Stouffer ${ }^{1}$

$\dagger$ Corresponding author:

alyssa.cirtwill@gmail.com; +468162000

${ }^{1}$ Centre for Integrative Ecology, School of Biological Sciences University of Canterbury Private Bag 4800

Christchurch 8140, New Zealand

${ }^{2}$ Present address: Department of Ecology, Environment, and Plant Sciences (DEEP) Stockholm University 11419 Stockholm, Sweden
${ }^{3}$ Biomathematics Research Centre, School of Mathematics and Statistics University of Canterbury Private Bag 4800 Christchurch 8140, New Zealand

${ }^{4}$ Department of Physics, Chemistry, and Biology (IFM) Linköping University 58183 Linköping, Sweden

\section{ORCID IDs}

Alyssa Cirtwill: https://orcid.org/0000-0002-1772-3868

Giulio V. Dalla Riva: https://orcid.org/0000-0002-3454-0633

Joshua A. Thia: https://orcid.org/0000-0001-9084-0959

Daniel B. Stouffer: https://orcid.org/0000-0001-9436-9674

Social media: @acirtwill; @stoufferlab

Header: Phylogenetic distance \& niche overlap

\section{Word Counts}

Main text: 6409

Figures: 3

- Introduction: 1163

Tables: 2

- Materials and Methods: 2469

Notes: 1 file, 6 sections.

- Results: 949

- Discussion: 1745

- Acknowledgements: 83 


\section{Summary}

- Related plants are often hypothesised to interact with similar sets of pollinators and herbivores, but this idea has only mixed empirical support. This may be because plant families vary in their tendency to share interaction partners.

- We quantify overlap of interaction partners for all pairs of plants in 59 pollination and 11 herbivory networks based on the numbers of shared and unshared interaction partners (thereby capturing both proportional and absolute overlap). We test 1) for relationships between phylogenetic distance and partner overlap within each network, 2) whether these relationships varied with the composition of the plant community, and 3) whether wellrepresented plant families showed different relationships.

- Across all networks, more closely-related plants tended to have greater overlap. The strength of this relationship within a network was unrelated to the composition of the network's plant component, but, when considered separately, different plant families showed different relationships between phylogenetic distance and overlap of interaction partners.

- The variety of relationships between phylogenetic distance and partner overlap in different plant families likely reflects a comparable variety of ecological and evolutionary processes. Considering factors affecting particular species-rich groups within a community may be the key to understanding the distribution of interactions at the network level.

\section{Keywords}

ecological networks, herbivory, niche overlap, phylogenetic signal, pollination, specialisation

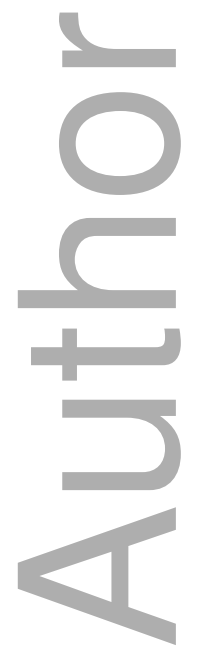




\section{Introduction}

1 Interactions with animals affect plants' life cycles in several critical ways (Mayr, 2001).

2 On one hand, pollination and other mutualistic interactions contribute to the reproductive success of many angiosperms (Ollerton et al., 2011). On the other, herbivores consume plant tissues (McCall \& Irwin, 2006) which costs plants energy and likely lowers their fitness (Strauss et al., 2002). In both cases, these interactions do not occur randomly but are strongly influenced by plants' phenotypes (Fontaine \& Thébault, 2015). For example, plants that produce abundant or high-quality nectar may receive more visits from pollinators (Robertson et al., 1999) whereas plants that produce noxious secondary metabolites may have fewer herbivores (Johnson et al., 2014). Plant traits are also likely to determine which specific pollinators and herbivores interact with a particular plant. Plants with different defences (e.g., thorns vs. chemical defences) may deter different groups of herbivores (Ehrlich \& Raven, 1964; Johnson et al., 2014), and pollinators with similar traits are often expected to attract similar sets of pollinators (Waser et al., 1996; Fenster et al., 2004; Ollerton et al., 2009).

If attractive and/or defensive traits are heritable, then we can reasonably expect that related plants will have similar patterns of interactions with animals, especially if there is some selection in either group to avoid competition or the number of potential partners is limited (Schemske \& Bradshaw, 1999; Ponisio et al., 2017). That is, there may be physimilar interaction partners. Recent studies that have investigated this question at the level of whole communities, however, have yielded mixed results. In particular, significant phylogenetic signal in plants' sets of interaction partners tends to be rare in empirical networks (Rezende et al., 2007b; Lind et al., 2015; Ibanez et al., 2016; but see Elias et al., 2013; Fontaine \& Thébault, 2015; Hutchinson et al., 2017). Moreover, statistically significant degrees of phylogenetic signal or coevolution may only result in small differences in network structure, adding to the difficulty of understanding patterns in species' in- 
teraction partners (Ponisio et al., 2017). Further, the plant and animal components of networks can show different degrees of phylogenetic conservation of interaction partners. In mutualistic networks, animals often show a stronger phylogenetic signal in their partners than do plants (Rezende et al., 2007b; Chamberlain et al., 2014; Rohr et al., 2014; Vamosi et al., 2014; Lind et al., 2015; Fontaine \& Thébault, 2015) (but see Rafferty \& Ives (2013) for a counterexample). In antagonistic networks, however, actively-foraging consumers tend to show less phylogenetic signal than their prey (Ives \& Godfray, 2006; Cagnolo et al., 2011; Naisbit et al., 2011; Fontaine \& Thébault, 2015). In part, this may be related to different degrees of interaction intimacy (dependence of one partner on another), which appears to contribute to network structure in mutualistic, but not antagonistic, networks (Guimarães et al., 2007; Ponisio et al., 2017). In any case, it is not straightforward to assume that interactions will always be similar among related species.

There are several mechanisms that might weaken the conservation of interaction partners. Pollination and herbivory may be affected by a wide variety of traits, and not all of these are likely to be phylogenetically conserved (Rezende et al., 2007a; Kursar et al., 2009; Ibanez et al., 2016). If, for example, floral displays are strongly affected by environmental conditions (Canto et al., 2004), then plant phylogeny may not strongly predict pollination. Even if the traits affecting pollination and herbivory are heritable, plants may experience conflicting selection pressures that weaken the overall association between plant phylogeny and interaction partners (Armbruster, 1997; Lankau, 2007; Siepielski et al., 2010; Wise \& Rausher, 2013; Kariñho-Betancourt et al., 2015). For instance, floral traits that are attractive to pollinators can also increase herbivory (Strauss et al., 2002; Adler \& Bronstein, 2004; Strauss \& Whittall, 2006; Theis, 2006). Conversely, herbivory can reduce pollination by inducing chemical defences (Adler et al., 2006) or altering floral display or nectar availability (Strauss, 1997). There may also be trade-offs between chemical and physical defences, or defences at different life stages, that weaken the overall heritability of plants' sets of herbivores (Kariñho-Betancourt et al., 2015; Endara et al., 2017). A 
plant's set of interaction partners therefore reflects a mixture of different environmental effects and different selection pressures, as well as shared phylogenetic history. If these factors affect closely-related plants differently, then closely-related species may not have more similar interaction partners than distantly-related species.

This variety of different pressures makes it likely that the relationship between plants' relatedness and the similarity of their interaction partners is not constant across plant clades. Closely-related plants in one clade might be under strong selection to favour dissimilar sets of pollinators to avoid exchanging pollen with other species (Levin \& Anderson, 1970; Bell et al., 2005; Mitchell et al., 2009), while plants in other clades may be under strong pressure to continue interacting with a common set of partners. Similarly, plants may experience disruptive selection on defences against herbivores if congeners tend to grow in the same places such that herbivore able to consume one species could easily spread to close relatives (Kursar et al., 2009; Yguel et al., 2014). On the other hand, unrelated plants might converge upon similar phenotypes which attract particularly efficient or abundant pollinators (Ollerton, 1996; Wilson et al., 2007; Ollerton et al., 2009; Ibanez et al., 2016). Likewise, unrelated plants may converge upon similar defences, leading them to share those herbivores which can overcome these defences (Pichersky \& Gang, 2000). In either case, dissimilarity of interactions among related species or similarity of interactions among unrelated species could result in weaker phylogenetic signal across an entire plant community. Moreover, all of the aforementioned hypotheses are non-exclusive; different processes likely affect different clades, and these processes might be associated with different pressures imposed by pollination and herbivory (Fontaine \& Thébault, 2015).

Here we investigate how overlap in interaction partners between pairs of plants (henceforth "niche overlap") varies over phylogenetic distance. Whereas previous studies have focused on the presence or absence of phylogenetic signal across entire networks, we take a pairwise perspective in order to obtain a more detailed picture of how plant phylogeny 
relates to network structure. As different plant families (which represent tractable clades for analysis) may have experienced different degrees of coevolution, convergence, etc., we also complement analyses with entire networks with comparisons among plants in the same family within a network. This novel perspective allows us to investigate the relationship between phylogenetic distance and partner overlap at different scales. Specifically, we test 1) whether niche overlap decreases over increasing phylogenetic distance in a large dataset of pollination and herbivory networks, 2) whether the plant family composition of a community affects the relationship between niche overlap and phylogenetic distance in that community, and 3) whether the relationship between niche overlap and phylogenetic distance differs systematically across plant families. This fine-grained approach gives more detailed information than previous studies.

\section{Materials and Methods}

\section{Network data}

We tested for phylogenetic signal in niche overlap within a set of 59 pollination and 11 herbivory networks. These networks span a range of biomes (desert to grassland to tundra) and countries (Sweden to New Zealand). The herbivory networks included a variety of types of herbivores but were dominated by leaf-chewing insects. Leaf-chewing and other types of herbivory might be affected by different plant traits and cannot be expected to show the same trends with respect to phylogeny. We therefore restricted our networks to leaf-chewing insects by removing any non-leaf chewing insects and any plants which had no interaction partners after removing other types of herbivores. The adjusted networks range in size between 19 and 997 total species (mean=162, median=97) with between 8 and 132 plant species (mean=39.1, median=29.5). See Table S1, Notes S1 for details on the original sources of all networks. All networks were qualitative and did not include interaction strengths. 


\section{Phylogenetic data}

In order to fit the plant species in all networks to a common phylogeny, we first compared all species and genus names with the National Center for Biotechnology Information and Taxonomic Name Resolution Service databases to ensure correctness. This was done using the function 'get_tsn' in the $\mathrm{R}$ ( $\mathrm{R}$ Core Team, 2016) package taxize (Chamberlain \& Szocs, 2013; Chamberlain et al., 2019). Species which could not be assigned to an accepted taxonomic name (e.g., 'Unknown Forb') were discarded, as were those with binomial names that could not be definitively linked to higher taxa (e.g., 'Salpiglossus sp.'). We were left with 2341 unique species in 1027 genera and 195 families. On average, $11.43 \%$ of plants were removed from each network (median $4.60 \%$, range $0-55.10 \%$ ).

We then estimated phylogenetic distances between the remaining species. To accomplish this, we constructed a phylogenetic tree based on a dated 'mega-tree' of angiosperms (Zanne et al., 2014). Some species in our dataset were not included in the angiosperm mega-tree. For angiosperms, a sister taxon was identified using Stevens (2001 onwards) and the species added manually. Ferns, tree ferns, and a single club moss were added to the base of the tree. This means that closely-related non-angiosperm species appear to have very long phylogenetic distances between them. We therefore excluded comparisons between pairs of non-angiosperms from our analyses. As only two networks (both herbivory networks) included more than one such species and non-angiosperms were always a small minority of any network, we do not believe that omitting these comparisons has greatly affected our results. To obtain trees for each network, we pruned the dated mega-tree to include only species in that network.

\section{Calculating niche overlap}

We calculated niche overlap for each pair of plants $i$ and $j$ based on the number of shared and unshared interaction partners $\left(M_{i j}, U_{i j}\right.$, respectively). The number of unshared interaction partners gives valuable information about cases where, for example, closely- 
related plants may have experienced disruptive selection, leading to weaker phylogenetic signal. The sum $M_{i j}+U_{i j}$ indicates the amount of information provided by each pair of plants: a pair of generalists which share most of their interaction partners gives a stronger indication of phylogenetic signal than a pair of extreme specialists with one common interaction partner.

Together, $M_{i j}$ and $U_{i j}$ give a Jaccard index $\left(J_{i j}\right)$ describing the proportion of shared interactions. $J_{i j}$ is defined:

$$
J_{i j}=\frac{M_{i j}}{U_{i j}+M_{i j}},
$$

where $M_{i j}$ is the set of mutual (shared) interaction partners and $U_{i j}$ the set of unshared interaction partners for plants $i$ and $j$. In our statistical analyses (see below), we used the tuple $\left(M_{i j}, U_{i j}\right)$ as the dependent variable rather than the single value $J_{i j}$. This allows us to preserve information about the amount of information provided by each pair of plants and weight the observations accordingly. Note that species sharing a large number of interaction partners may not share a large proportion of interaction partners if the number of interaction partners that are not shared is also large.

\section{Testing conservation of niche overlap within networks}

We modelled the relationship between niche overlap and phylogenetic distance using a logistic regression. We used the numbers of shared $\left(M_{i j}\right)$ and non-shared $\left(U_{i j}\right)$ partners as dependent variables and centred, scaled phylogenetic distance as the independent variable. This approach is conceptually similar to modelling successes and failures in a binomialdistributed process. Accordingly, we assumed a binomially-distributed error structure and used a logit link function to model the dissimilarity in interaction partners $J_{i j}$ of plants $i$ and $j$. Regressions of niche overlap and phylogenetic distance within each network were fit using the R (R Core Team, 2016) base function "glm" and took the form

$$
\operatorname{logit}\left(J_{i j}\right) \propto \beta_{\text {distance }} \delta_{i j},
$$


where $\delta_{i j}$ is the phylogenetic distance between plants $i$ and $j$ and $J_{i j}$ is defined by the tuple $\left(M_{i j}, U_{i j}\right)$ (see Notes S2 for R implementation). The fixed effect of distance in this regression, $\beta_{\text {distance }}$, can be understood as the change in log odds of sharing an interaction partner per million-year change in phylogenetic distance.

These separate regressions avoid the potential for confounding the effects of different relationships in different networks. As we also wished to evaluate the overall trend across networks, we fit an additional regression of niche overlap and phylogenetic distance across all network types. As well as the fixed effect of phylogenetic distance, this regression included fixed effects of network type (pollination or herbivory) and the interaction between phylogenetic network type and random intercepts and slopes per network. This expanded regression was fit using the R (R Core Team, 2016) function 'glmer' from package lme4 (Bates et al., 2015) and took the form

$$
\operatorname{logit}\left(J_{i j}\right) \propto \beta_{\text {distance }} \delta_{i j}+\beta_{\text {pollination }} I_{i j}+\beta_{\text {distance:pollination }} \delta_{i j} I_{i j},
$$

where $I_{i j}=1$ when plants $i$ and $j$ are drawn from a pollination network and $I_{i j}=0$ when $i$ and $j$ are drawn from a herbivory network, and all other symbols are as above. Note that we only compared pairs of plants taken from the same network. The fixed effects $\beta_{\text {pollination }}$ and $\beta_{\text {distance:pollination }}$ are the change in intercept and slope of the log odds of sharing an interaction partner, respectively, relative to the baseline of herbivory networks.

To demonstrate the power of defining $J_{i j}$ as a tuple of $M_{i j}$ and $U_{i j}$ rather than a single value, we repeated the above analyses using a Jaccard index based only on the proportion of interaction partners that are shared (i.e., $J_{i j}=M_{i j} /\left[M_{i j}+U_{i j}\right]$ ). Note that while the proportion of shared interaction partners is the same in both cases, the tuple formulation gives more weight to plants with many interaction partners as these provide more information. When comparing the two approaches we observed similar trends but, notably, the tuple definition of $J_{i j}$ had greater power to detect weak relationships (Notes S3). We therefore show only the results when defining $J_{i j}$ as a tuple in the main text. 
To test whether the relationship between phylogenetic distance and niche overlap depended on network size, we fit a general linear model for the slope of this relationship inferred from the glm models against the number of plant pairs for which distances could be calculated (hereafter "network size"), network type (again using herbivory networks as a baseline), and their interaction:

$$
\beta_{\text {distance }} \propto \beta_{\text {size }} \eta_{N}+\beta_{\text {pollination }} I_{N}+\beta_{\text {size:pollination }} \eta_{N} I_{N}
$$

where $\eta_{N}$ is the number of plant pairs in network $N$ for which distances could be calculated, $I_{N}$ is an indicator equal to 1 if network $N$ is a pollination network and 0 otherwise.

As the interaction between network type and network size was strong and opposite to the direction of the main effect of network size, we fit an additional general linear model using only data from pollination networks and including only the effect of network size (herbivory networks were the baseline in the full glm). Both models were fit using the R (R Core Team, 2016) base function "glm". A similar model relating the strength of the relationship between phylogenetic distance and niche overlap to connectance showed no significant trends (Notes $S_{4}$ ).

\section{Accounting for non-independence}

Note that pairs of plants are not independent: the same plant will appear in many pairs, and interactions may be influenced by the overall structure of the community. This violates the assumptions used when calculating the significance of logistic regressions within the R (R Core Team, 2016) base package or the package lme4 (Bates et al., 2015). To fairly estimate the significance of our regressions, it was therefore necessary to compare the observed relationships to those in a suite of appropriately permuted networks. To create these networks, we shuffled interactions among species while preserving row and column totals. Each species retained the same number of interaction partners as in the observed network but the exact set of partners (and therefore niche overlaps with all 
other species) varied across permuted networks. We preserved the observed phylogenetic relationships between species in all cases. For each observed network, we created 999 such permuted networks and calculated the relationship between niche overlap and phylogenetic distance. This gave us a null distribution for each observed network with which to determine the significance of the observed relationship.

This permutation approach also allows us to estimate type I and type II error for our analysis. Because the permuted networks should not demonstrate any particular relationship between phylogenetic distance and partner overlap, these slopes should be similar to those obtained after permuting these networks a second time. To estimate type I and type II errors, we created 500 permutations of each permuted network and, again keeping the observed phylogenetic distances between plant species, repeated our analyses. We then determined the number of permuted networks which appear to have significant overlap-phylogenetic distance relationships relative to the permutations of these permuted networks (type I error). Type II error can be determined from the distribution of $p$ values obtained when comparing the permuted networks to permutations of the permuted networks. Although calculating the exact type II error requires a specific alternative hypothesis, the uniform distribution of $p$-values we obtained after permuting the permuted networks means that the type II error would increase linearly as the alternative hypothesis was set farther from zero (Notes S5).

\section{Linking network-level trends and community composition} Next, we-examined the connection between our network-level observations and the number of species in each plant family present in each community. Specifically, we tested the hypothesis that varying relationships between phylogenetic distance and pairwise niche overlap are due to the different distributions of families across networks. We defined the relationship between phylogenetic distance and niche overlap as the change in log odds of two plants in a given network sharing an interaction partner per million years 
of divergence (i.e., the slope $\beta_{\text {distance }}$ from the regression of niche overlap against phylogenetic distance within a single network). We then related differences in this relationship to differences in Bray-Curtis dissimilarity in the family-wise composition of the two plant communities using a non-parametric permutational multi-variate analysis of variance (PERMANOVA; Anderson, 2001). Bray-Curtis dissimilarity considers only those plant families which appear in at least one of a pair of networks (Anderson, 2001; Cirtwill \& Stouffer, 2015), ensuring that the shared absence of rare plant families will not make two networks appear more similar than they actually are.

Note that a PERMANOVA does not assume that the data are normally distributed, but rather compares the pseudo- $F$ statistic calculated from the observed data to a null distribution obtained by permuting the raw data. As pollination and herbivory networks might have different community composition, we stratified these permutations by network type. That is, the response variable of change in log odds for a pollination network could only be exchanged for that of another pollination network. This stratification procedure ensures that the null distribution used to calculate the $P$-value is not biased by including combinations of changes in log odds and community composition that would not occur because of inherent differences in the two network types (e.g., Pinaceae only appeared in herbivory networks and should not be assigned to pollination networks). We used 9999 such stratified permutations to obtain the null distribution and obtain a $P$-value.

\section{Calculating niche overlap within families}

Finally, we compared the breakdown of niche overlap in different plant families. Withinfamily genetic and trait diversity can be high due to adaptive radiations, heterogeneous selection, and other influences on different species. Plant families offer a reasonable balance between collecting enough species to identify meaningful trends and maintaining a tractable number of analyses. They are therefore the best taxonomic level to investigate phylogenetic conservation in more detail across our large dataset. To test whether dif- 
ferent families show different conservation of interactions, we used the same definitions of overlap and phylogenetic distance as in the within-network analysis but restricted our regressions to pairs of plants from the same family and the same network. Unlike in our previous analysis, we analysed data from pollination and herbivory networks separately as most well-represented plant families appeared in only one network type. For those families which appeared in both network types, we ran separate analyses on each subset of data.

For each plant family, within each network type, we fit one of two similar sets of models. If family $f$ was found in several networks of the same type (e.g., several pollination networks), we fit a mixed-effects logistic regression relating niche overlap to a fixed effect of phylogenetic distance and a random effect for each network using the $\mathrm{R}$ ( $\mathrm{R}$ Core Team, 2016) function "glmer" from package lme4 (Bates et al., 2015). If family $f$ was found in only one network, we omitted the network-level random effect and fit a logistic regression using the R (R Core Team, 2016) base function "glm". These equations took the same form as equation 2 .

Models for two families did not converge. In the Lauraceae, (represented by four species in one pollination network) and the Sapindaceae (represented by five species in one herbivory network and five species in two pollination networks), only one pair of species per network type shared any interaction partners while all other pairs did not share any interaction partners.

By considering each family separately, we do risk obtaining some significant results purely by chance. The standard technique for addressing this type of multiple hypothesis testing, the Bonferroni correction, tends to be over-zealous and lead to a failure to reject the null hypothesis even when a large number of significant results before the correction supports the alternative hypothesis (Moran, 2003). To account for multiple testing while also allowing the number of families showing significant trends to carry some weight, we use the correlated Bonferroni test introduced in Drezner \& Drezner (2016) (Notes S6). 


\section{Results}

\section{Within-network conservation of niche overlap}

Across all networks, more distantly-related plants were less likely to share interaction partners $\left(\beta_{\text {distance }}=-6.82, p<0.001\right)$. Plants in pollination networks tended to share fewer interaction partners overall, and the decrease in overlap with increasing phylogenetic distance was steeper $\left(\beta_{\text {pollination }}=-1.44, p<0.001\right.$ and $\beta_{\text {distance:pollination }}=-18.5, p<0.001$, respectively). That is, a pair of plants in the same genus was more likely to share interaction partners than a pair of plants in the same family in both types of networks, but a pair of congeners would be less likely to share pollinators than to share herbivores. Note that, as our networks are qualitative, these results refer only to the number of shared interaction partners rather than to the quantitative strength of competition.

As an illustration, a pair of plants which diverged 10mya would have a probability of 0.202 of sharing a given herbivore and 0.094 of sharing a given pollinator, while a pair of plants which diverged 750mya would have a probability of 0.121 of sharing a given herbivore or 0.011 of sharing a given pollinator. These trends may be related to the numbers of extreme specialists in each network. In our dataset, an average of $48 \%(+/-$ 14) of pollinators in a given web were extreme specialists (i.e., visited only one plant species) compared to $29 \%(+/-29)$ of herbivores $(z=5.62, \mathrm{df}=68, P<0.001$ for a binomial regression of specialists and generalists over network type).

Despite these general trends, there was substantial variation between pollination networks, with overlap of interaction partners decreasing with increasing phylogenetic distance in some networks and increasing in others (Fig. 1). Overlap of interaction partners decreased significantly with increasing phylogenetic distance in $7 / 11$ herbivory networks and $33 / 59$ pollination networks. In the remaining four herbivory networks and 25 of the 26 remaining pollination networks, overlap of interaction partners was not related to phylogenetic distance. Overlap of interaction partners increased with increasing phylogenetic 
distance in only a single pollination network.

The slope of the relationship between phylogenetic distance and overlap of interaction partners was related to the number of plant pairs in herbivory, but not pollination, networks. Larger herbivory networks had higher values of $\beta_{\text {distance }}\left(\beta_{\text {size }}=2.58 \times 10^{-4}, p=0.011\right.$ for the full glm; herbivory networks are the baseline). Pollination networks had higher (less negative) slopes overall $\left(\beta_{\text {pollinator }}=0.306, p<0.001\right.$ compared to the intercept value of -0.434 for herbivory networks). Pollination networks moreover showed a much weaker relationship between network size and the strength of the overlap-distance relationship ( $\left.\beta_{\text {pollination:size }}=-2.64 \times 10^{-4}, p=0.009\right)$. After refitting the glm to the pollination networks alone, there was no significant relationship between network size and the slope of the overlap-distance relationship $\left(\beta_{\text {size }}=-5.91 \times 10^{-6}, p=0.572\right)$.

Comparing the results in the observed networks to those obtained after permuting interactions, the observed slope of the relationship between phylogenetic distance and interaction partner overlap was always more extreme (i.e., always more negative or always more positive) than that obtained in the permuted networks (Fig. 2). Observed networks with a negative relationship between phylogenetic distance and overlap always had a more negative slope than that obtained from the permuted networks, while the 10 networks with positive relationships between phylogenetic distance and overlap always had more positive relationships than the permuted networks. This indicates that even in the networks with non-significant relationships, the association between niche overlap and phylogenetic distance was not random and confirms that the significant results we observe are not due to non-independence of plants within a network. When the slopes of the permuted networks were compared to those obtained from permutations of the permuted networks, there was no relationship, which speaks to the robustness of our methodology (Notes S5). 


\section{Linking network-level trends and community composition}

We were interested in whether the slope of the relationship between phylogenetic distance and niche overlap varied with community composition. In a PERMANOVA of slope against community composition, stratified by network type, we did not find a significant relationship between slope and community composition $\left(F_{1,68}=1.06, p=0.493\right)$. Of the 200 families in our dataset, only 29 were represented by more than 20 species. Lumping all other families into an "other" category and repeating the PERMANOVA, we still did not find a significant relationship between slope and community composition $\left(F_{1,68}=1.12\right.$, $p=0.409)$

\section{Within-family conservation of niche overlap}

Taking all families together, the probability of species in the same family sharing interaction partners was not significantly related to phylogenetic distance $\left(\beta_{\text {distance }}=-6.48\right.$, $p=0.087)$. Pollination networks did not show a significantly different slope from the herbivory networks $\left(\beta_{\text {distance:pollination }}=1.73, p=0.681\right)$. Plants in pollination networks did, however, have a lower intercept probability of sharing interaction partners $\left(\beta_{\text {pollination }}=-\right.$ $0.776, p=0.007)$, similar to our within-network results above.

Considering each family separately, the relationship between within-family niche overlap and phylogenetic distance varied widely in both pollination and herbivory networks. In pollination networks, overlap decreased significantly with increasing phylogenetic distance in 14 of the 48 well-represented families (Table 1; Fig. 3). If we apply the correlated Bonferroni correction to account for multiple testing (Drezner \& Drezner, 2016), all of these slopes remain significant (Notes S6). There was no significant relationship between overlap and phylogenetic distance in a further 34 plant families (see Notes $S 6$ for further details). Finally, the overlap between pairs of Apiaceae and Poaceae increased significantly with increasing phylogenetic distance.

Of the nine plant families that were well-represented in herbivory networks, overlap 
decreased significantly with increasing phylogenetic distance in four (Table 2; Fig. 3). Four families did not show significant relationships between phylogenetic distance and overlap, and in one family, Fabaceae, overlap of interaction partners increased significantly with increasing phylogenetic distance. If we again apply the correlated Bonferroni correction, all five significant slopes remain significant (Supportin information 6).

\section{Discussion}

We found general support for the hypothesis that more closely-related pairs of plants have a higher degree of niche overlap. Taking all networks together, the probability of two plants sharing the same animal interaction partners decreased with increasing phylogenetic distance. Considering networks separately, $\approx 56 \%$ of pollination and $\approx 64 \%$ of herbivory networks showed the expected trend of decreasing overlap with increasing distance. This variation between networks echoes earlier studies (e.g., Fontaine \& Thébault, 2015; Hutchinson et al., 2017), which also found broad evidence for phylogenetic conservation of interaction partners despite variation between particular networks. The lack of a significant relationship between phylogenetic distance and niche overlap in many networks could be partly due to the large number of extreme specialist insects, especially in the pollination networks. These species interact with only one plant and therefore weaken any signal of niche overlap. The herbivory networks did not contain as many obligate specialists, but we note that herbivores, like pollinators, often interact with only a few closely-related plants (Novotny \& Basset, 2005; Brändle \& Brandl, 2006; Astegiano et al., 2017). These oligotrophs may affect overall phylogenetic signal in the same way as the strict specialists: in both cases plants that are not very closely related are unlikely to share interaction partners. Note that some of the apparent specialists in our dataset may actually be rare species involved in more interactions which have not yet been observed (Blüthgen et al., 2006; Poisot et al., 2015). Without information on the sampling completeness of the networks in our dataset, it is difficult to estimate the size of this effect. 
It is possible, however, that we might observe stronger relationships between phylogenetic distance and niche overlap with more complete data on rare species.

In our dataset, the slope of the relationship between phylogenetic distance and niche overlap was not related to the composition of the plant community in each network. Combined with the overall trend for conservation of interaction partners above, this suggests that trends among closely-related plants (e.g., congeners or members of the same subfamilies) are more important than phylogenetic signal from deeper within the phylogenetic tree. This echoes earlier results relating plant phylogeny to predation by particular insect species (Novotny et al., 2002, 2004; Ødegaard et al., 2005) and in whole herbivory networks (Volf et al., 2017). As we did not find any relationship between the families present in a network and the relationship between phylogenetic distance and niche overlap in either pollination or herbivory networks, the greater importance of shallow phylogeny (as reported for leaf miners and gallers in Volf et al. (2017)) may be a general feature of plant-insect interaction networks. This contrasts with Chamberlain et al. (2014), who found that the shape of the phylogenetic tree had a larger effect on network structure than the timing of speciation. As Chamberlain et al. (2014) were interested in overall structural properties of networks rather than niche overlap, this discrepancy may indicate that different aspects of plant-insect interaction networks are influenced by different aspects of plant phylogenies.

The variability of the strength of phylogenetic signal across networks and the lack of influence of community composition on the strength of this signal could be partly due to different trends within families. More than half of the plant families in each network type behaved as we hypothesised, with more closely-related plants having greater niche overlap than distantly related plants. This relationship between overlap and phylogenetic distance is consistent with the idea that traits affecting interactions are heritable and change gradually such that closely related plants resemble their common ancestorand each other - more than they do distantly related plants (Schemske \& Bradshaw, 
1999; Gilbert et al., 2015; Ponisio et al., 2017). The degree of heritability of key traits may, however, differ between families. In some families, such as Asteraceae in pollination networks, the positive slope of this relationship was very shallow while in others, such as Melastomataceae in herbivory networks, the positive slope was extremely steep. This could indicate different rates of phenotypic drift or evolution in different families (or their interaction partners). In other families, there was no significant relationship between phylogenetic distance and niche overlap. In these cases, key traits affecting plant-insect interactions may be highly labile or plastic (environmentally determined). These possibilities are supported by several studies showing a stronger relationship between niche overlap and trait similarity than niche overlap and phylogenetic similarity (Junker et al., 2015; Ibanez et al., 2016; Endara et al., 2017).

While the majority of plant families in our dataset showed the expected trend, two (Polygonaceae in pollination networks and Fabaceae in herbivory networks) showed the opposite pattern. In these families, closely-related plants had lower overlap than more distantly-related pairs of plants. There are several possible explanations for this pattern. First, part of the family may have recently undergone a period of rapid diversification with closely-related species developing novel phenotypes and attracting different interaction partners (Linder, 2008; Breitkopf et al., 2015). Likewise, the animals may have undergone an adaptive radiation to specialise on their most profitable partner (Janz et al., 2006). Alternatively, plants in these families could have undergone convergent evolution or ancestral traits could be strongly preserved. Either case would allow distantly-related Polygonaceae and Fabaceae to interact with the same insects. Finally, this pattern could be the result of ecological or environmental filtering (Ackerly, 2003; Mayfield et al., 2009). Closely-related species with strong niche overlap might compete too severely to coexist. This is especially likely for plants sharing pollinators, where the loss of pollen to related species might severely limit reproductive success (Levin \& Anderson, 1970; Bell et al., 2005; Mitchell et al., 2009). Indeed, animal pollination and seed dispersal have 
been shown to act as filters for several plant clades (Mayfield et al., 2009). Selection to avoid competition and restrict numbers of interaction partners may lead to more intimate or specialised interactions (Ponisio et al., 2017). This is particularly the case in highly intimate interactions, where both partners may specialise (Hembry et al., 2018). Past selection to avoid competition is consistent with the relatively high proportion of extreme specialists we observed in the pollination networks. As described above, these specialists likely weaken the relationship between phylogenetic distance and niche overlap.

The remaining families did not show significant relationships in either direction. That is, the niche overlap between two plants did not vary linearly over phylogenetic distance. Once again, there are several possible explanations for this result. These plants might be highly specialised on different interaction partners and therefore have low overlap at all levels of relatedness. In other plant families with more moderate levels of specialisation, it is possible that pollination and/or herbivory do not exert large selection pressures on the plants. If traits affecting pollination or herbivory are not heritable in these groups [Kursar et al., 2009] or their phenotypes are constrained by other factors (e.g., environmental conditions, trade-offs with other traits, ontogenic change [Kariñho-Betancourt et al., 2015]), then we should not expect a relationship between phylogenetic distance and overlap of interaction partners. Alternatively, pollination and/or herbivory might exert large pressures that maintain the clade within a single pollination or defensive syndrome. These syndromes are commonly believed to predict the pollinators or herbivores with which a plant will interact (Waser et al., 1996; Fenster et al., 2004; Ollerton et al., 2009; Johnson et al., 2014). As some recent studies have suggested that pollination syndromes do not accurately predict plants' visitors in all plant families (Ollerton et al., 2009), it may be of interest for future researchers to test whether syndromes are better predictors in families with weak relationships between overlap and phylogenetic distance.

For those few families which were well-represented in both pollination and herbivory networks, we can also contrast the trends in the two network types. Notably, all families 
except Asteraceae showed different trends in different network types. This could be because of conflicting selection from pollinators and herbivores, with one type of selection ( placing greater constraints on plant traits than the other. Multiple types of interactions (e.g., pollination, herbivory, nectar robbing) and even environmental factors can influence traits such as flower colour, nectar abundance, and flowering phenology (Strauss \& Whittall, 2006). These influences can act in the same or different directions (Strauss \& Whittall, 2006). Plant phenotypes in turn affect which species participate in both pollination and herbivory (Strauss, 1997; Strauss et al., 2002; Adler \& Bronstein, 2004; Adler et al., 2006; Theis, 2006). The interplay between these different selective pressures may mean that plants cannot evolve to respond optimally to both pollinators and herbivores. Put another way, stronger selective pressure from herbivores might cause phenotypic changes that disrupt phylogenetic signal in pollinators, or vice versa. This could result from asymmetric degree distributions: within a single system, most plants tend to interact with many pollinators or many herbivores but not both (Melián et al., 2009; Pocock et al., 2012; Astegiano et al., 2017). These asymmetric interactions may also affect higher-order network structures such as modularity or nestedness (Astegiano et al., 2017). The nature of the effects of multiple interaction types on both phylogenetic signal in interactions and overall network structure is, however, still an open question deserving of much more research.

Altogether, our study has revealed general trends for conservation of interaction partners between closely-related species, with some networks and plant families showing different trends. This overall similarity between closely-related species has a potential application in ecological restoration. Close relatives could be used interchangeably to restore missing interactions and fill ecosystem functions. This may be advantageous when a target plant is more difficult to establish than its relatives, or if the restoration site is not large enough to support viable populations of many species. We should urge caution, however, since plants which support the same pollinators may also support similar sets 
of herbivores. To avoid unwanted indirect effects, all interactions involving the target species should be considered. Although here we considered only the presence or absence of interactions, (i.e., qualitative networks) recent work also suggests that the phylogenetic composition of a plant community can also affect the strength of interactions, and that the spatial arrangement of plants within a community may be particularly important (Yguel et al., 2011; Castagneyrol et al., 2014). These further nuances in the relationship between phylogenetic distance and niche overlap could also strongly affect the ability of closelyrelated species to fill the same functions in restoration efforts. This is clearly a topic with many unresolved questions, deserving of further study.

\section{Acknowledgements}

We thank Christie J. Webber for comments on the design of the study and for data collection. We also thank the authors of the published networks used in this study. We are grateful for the use of the Edward Percival field station in Kaikoura, New Zealand in May, 2014. This research was supported by an NSERC PGS-D graduate scholarship (to ARC), a Marsden Fund Fast-Start grant (UOC-1101) and a Rutherford Discovery Fellowship, both administered by the Royal Society of New Zealand (to DBS), a BlueFern HPC PhD scholarship (to NJB), and by the Allan Wilson Centre (to GVDR).

\section{Author Contribution}

ARC, DBS, GVDR, and NJB designed the research. ARC, MO, IN, IMW, and JAT collected published data. ARC and GVDR performed the analyses. All authors contributed to the manuscript. 


\section{References}

Ackerly D. 2003. Community assembly, niche conservatism, and adaptive evolution in changing enyironments. International Journal of Plant Sciences 164: S165-S184.

Adler LS \& Bronstein JL. 2004. Attracting antagonists: does floral nectar increase leaf herbivory? Ecology 85: 1519-1526.

Adler LS, Wink M, Distl M \& Lentz AJ. 2006. Leaf herbivory and nutrients increase nectar alkaloids. Ecology Letters 9: 960-967.

Anderson MJ. 2001. A new method for non-parametric multivariate analysis of variance. Austral Ecology 26: 32-46.

Armbruster WS. 1997. Exaptations link evolution of plant-herbivore and plant-pollinator interactions: a phylogenetic inquiry. Ecology 78: 1661-1672.

Astegiano J, Altermatt F \& Massol F. 2017. Disentangling the co-structure of multilayer interaction networks: degree distribution and module composition in two-layer bipartite networks. Scientific Reports 7: 15465.

Bates D, Mächler M, Bolker B \& Walker S. 2015. Fitting linear mixed-effects models using lme4. Journal of Statistical Software 67: 1-48.

Bell JM, Karron JD \& Mitchell RJ. 2005. Interspecific competition for pollination lowers seed production and outcrossing in Mimulus ringens. Ecology 86: 762-771.

Blüthgen N, Menzel F \& Blüthgen N. 2006. Measuring specialization in species interaction networks. BMC Ecology 6: 9.

This article is protected by copyright. All rights reserved 
Brändle M \& Brandl R. 2006. Is the composition of phytophagous insects and parasitic fungi among trees predictable? Oikos 113: 296-304.

\section{Breitkopf H, Onstein RE, Cafasso D, Schlüter PM \& Cozzolino S. 2015.} Multiple shifts to different pollinators fuelled rapid diversification in sexually deceptive Ophrys orchids. New Phytologist 207: 377-389.

Cagnolo L, Salvo A \& Valladares G. 2011. Network topology: patterns and mechanisms in plant-herbivore and host-parasitoid food webs. Journal of Animal Ecology 80: 342-351.

Canto A, Parra-Tabla V \& García-Franco JG. 2004. Variations in leaf production and floral display of Anthurium schlechtendalii (Araceae) in response to herbivory and environment. Functional Ecology 18: 692-699.

Castagneyrol B, Jactel H, Vacher C, Brockerhoff EG \& Koricheva J. 2014. Effects of plant phylogenetic diversity on herbivory depend on herbivore specialization. Journal of Applied Ecology 51: 134-141.

Chamberlain S, Szoecs E, Foster Z, Arendsee Z, Boettiger C, Ram K, Bartomeus I, Baumgartner J, O'Donnell J, Oksanen J, Tzovaras BG, Marchand P, Tran V, Salmon M, Li G \& Grenié M. 2019. taxize: taxonomic information from around the web. R package version 0.9.7. URL: https://github.com/ropensci/taxize.

Chamberlain SA, Cartar RV, Worley AC, Semmler SJ, Gielens G, Elwell S, Evans ME, Vamosi JC \& Elle E. 2014. Traits and phylogenetic history contribute to network structure across Canadian plant-pollinator communities. Oecologia 176: 545-556.

This article is protected by copyright. All rights reserved 
Chamberlain SA \& Szocs E. 2013. taxize - taxonomic search and retrieval in R. F1000Research 2. doi: 10.12688/f1000research.2-191.v2

Cirtwill AR \& Stouffer DB. 2015. Concomitant predation on parasites is highly variable but constrains the ways in which parasites contribute to food web structure. Journal of Animal Ecology 84: 734-744.

Drezner Z \& Drezner TD. 2016. A remedy for the overzealous Bonferroni technique for multiple statistical tests. The Bulletin of the Ecological Society of America 97: $91-98$.

Ehrlich PR \& Raven PH. 1964. Butterflies and plants: a study in coevolution. Evolution 18: 586-608.

Elias M, Fontaine C \& van Veen FJF. 2013. Evolutionary history and ecological processes shape a local multilevel antagonistic network. Current Biology 23:

$1355-1359$.

Endara MJ, Coley PD, Ghabash G, Nicholls JA, Dexter KG, Donoso DA, Stone GN, Pennington RT \& Kursar TA. 2017. Coevolutionary arms race versus host defense chase in a tropical herbivore-plant system. Proceedings of the National Academy of Sciences 114: E7499-E7505.

Fenster CB, Armbruster WS, Wilson P, Dudash MR \& Thomson JD. 2004. Pollination syndromes and floral specialization. Annual Review of Ecology, Evolution, and Systematics 35: 375-403.

Fontaine C \& Thébault E. 2015. Comparing the conservatism of ecological 
interactions in plant-pollinator and plant-herbivore networks. Population Ecology 57: $29-36$.<smiles>[Li][Mg]</smiles>

Gilbert GS, Briggs HM \& Magarey R. 2015. The impact of plant enemies shows a phylogenetic signal. PLoS One 10: e0123758.

Guimarães Jr. PR, Rico-Gray V, Oliveira PS, Izzo TJ, dosReis SF \& Thompson JN. 2007. Interaction intimacy affects structure and coevolutionary dynamics in mutualistic networks. Current Biology 17: 1797-1803.

\section{Hembry DH, Raimundo RLG, Newman EA, Atkinson L, Guo C, Guimarães} Jr. PR \& Gillespie RG. 2018. Does biological intimacy shape ecological network structure? A test using a brood pollination mutualism on continental and oceanic islands. Journal of Animal Ecology 87: 1160-1171.

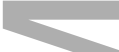

Hutchinson-MC, Cagua EF \& Stouffer DB. 2017. Cophylogenetic signal is detectable in pollination interactions across ecological scales. Ecology 98: 2640-2652.

Ibanez S, Arène F \& Lavergne S. 2016. How phylogeny shapes the taxonomic and functional structure of plant-insect networks. Oecologia 180: 989-1000.

Ives AR \& Godfray HCJ. 2006. Phylogenetic analysis of trophic associations. The American Naturalist 168: E1-E14.

Janz N, Nylin S \& Wahlberg N. 2006. Diversity begets diversity: host expansions and the diversification of plant-feeding insects. BMC Evolutionary Biology 6: 4 .

Johnson MTJ, Ives AR, Ahern J \& Salminen JP. 2014. Macroevolution of plant defenses against herbivores in the evening primroses. New Phytologist 203: 267-279.

This article is protected by copyright. All rights reserved 
Junker RR, Blüthgen N \& Keller A. 2015. Functional and phylogenetic diversity of plant communities differently affect the structure of flower-visitor interactions and reveal convergences in floral traits. Evolutionary Ecology 29: 437-450.

\section{Kariñho-Betancourt E, Agrawal AA, Halitschke R \& Núñez-Farfán J. 2015.} Phylogenetic correlations among chemical and physical plant defenses change with ontogeny. New Phytologist 206: 796-806.

Kursar TA, Dexter KG, Lokvam J, Pennington RT, Richardson JE, Weber MG, Murakami ET, Drake C, McGregor R \& Coley PD. 2009. The evolution of antiherbivore defenses and their contribution to species coexistence in the tropical tree genus Inga. Proceedings of the National Academy of Sciences 106: 18073-18078.

Lankau RA. 2007. Specialist and generalist herbivores exert opposing selection on a chemical defense. New Phytologist 175: 176-184.

Levin DA \& Anderson WW. 1970. Competition for pollinators between simultaneously flowering species. The American Naturalist 104: 455-467.

\section{Lind EM, Vincent JB, Weiblen GD, Cavender-Bares J \& Borer ET. 2015.} Trophic phylogenetics: evolutionary influences on body size, feeding, and species associations in grassland arthropods. Ecology 96: 998-1009.

Linder HP. 2008. Plant species radiations: where, when, why? Philosophical Transactions of the Royal Society of London B: Biological Sciences 363: 3097-3105.

Mayfield MM, Boni MF \& Ackerly DD. 2009. Traits, habitats, and clades: identifying traits of potential importance to environmental filtering. The American Naturalist 174: E1-E22. 
Mayr E. 2001. What Evolution is. New York: Basic Books.

McCall AC \& Irwin RE. 2006. Florivory: the intersection of pollination and herbivory. Ecology Letters 9: 1351-1365.

Melián CJ, Bascompte J, Jordano P \& Křivan V. 2009. Diversity in a complex ecological network with two interaction types. Oikos 118: 122-130.

Mitchell RJ, Flanagan RJ, Brown BJ, Waser NM \& Karron JD. 2009. New frontiers in competition for pollination. Annals of Botany 103: 1403-1413.

Moran MD. 2003. Arguments for rejecting the sequential Bonferroni in ecological studies. Oikos 100: 403-405.

Naisbit RE, Kehrli P, Rohr RP \& Bersier LF. 2011. Phylogenetic signal in predator-prey body-size relationships. Ecology 92: 2183-2189.

Novotny V \& Basset Y. 2005. Host specificity of insect herbivores in tropical forests. Proceedings of the Royal Society B: Biological Sciences 272: 1083-1090.

Novotny V, Basset Y, Miller SE, Weiblen GD, Bremer B, Cizek L \& Drozd P. 2002. Low host specificity of herbivorous insects in a tropical forest. Nature 416: $841-844$.

Novotny V, Miller SE, Leps J, Basset Y, Bito D, Janda M, Hulcr J, Damas K \& Weiblen GD. 2004. No tree an island: the plant-caterpillar food web of a secondary rain forest in New Guinea. Ecology Letters 7: 1090-1100.

Ødegaard F, Diserud OH \& Østbye K. 2005. The importance of plant relatedness for host utilization among phytophagous insects. Ecology Letters 8: 612-617.

This article is protected by copyright. All rights reserved 
Ollerton J. 1996. Reconciling ecological processes with phylogenetic patterns: the apparent paradox of plant-pollinator systems. Journal of Ecology 84: 767-769.

Ollerton J, Alarcón R, Waser NM, Price MV, Watts S, Cranmer L, Hingston A, Peter CI \& Rotenberry J. 2009. A global test of the pollination syndrome hypothesis. Annals of Botany 103: 1471-1480.

Ollerton J, Winfree R \& Tarrant S. 2011. How many flowering plants are pollinated by animals? Oikos 120: 321-326.

Pichersky E \& Gang DR. 2000. Genetics and biochemistry of secondary metabolites in plants: an evolutionary perspective. Trends in Plant Science 5: 439-445.

Pocock MJO, Evans DM \& Memmott J. 2012. The robustness and restoration of a network of ecological networks. Science 335: 973-977.

Poisot T, Stouffer DB \& Gravel D. 2015. Beyond species: Why ecological interaction networks vary through space and time. Oikos 124: 243-251.

Ponisio LC, Gaiarsa MP \& Kremen C. 2017. Opportunistic attachment assembles plant-pollinator networks. Ecology Letters 20: 1261-1272.

R Core Team. 2016. $R$ : a language and environment for statistical computing. Vienna, Austria: R Foundation for Statistical Computing.

Rafferty NE \& Ives AR. 2013. Phylogenetic trait-based analyses of ecological networks. Ecology 94: 2321-2333.

Rezende EL, Jordano P \& Bascompte J. 2007a. Effects of phenotypic complementarity and phylogeny on the nested structure of mutualistic networks. Oikos 116: 1919-1929.

This article is protected by copyright. All rights reserved 
Rezende EL, Lavabre JE, Guimarães PR, Jordano P \& Bascompte J. 2007b.

Non-random coextinctions in phylogenetically structured mutualistic networks.

Nature 448: 925-928.

\section{Robertson AW, Mountjoy C, Faulkner BE, Roberts MV \& Macnair MR.}

1999. Bumble bee selection of Mimulus guttatus flowers: the effects of pollen quality and reward depletion. Ecology 80: 2594-2606.

Rohr RP, Saavedra S \& Bascompte J. 2014. On the structural stability of mutualistic systems. Science 345: 1253497.

Schemske DW \& Bradshaw Jr. HD. 1999. Pollinator preference and the evolution of floral traits in monkeyflowers (Mimulus). Proceedings of the National Academy of Sciences 96: 11910-11915.

Siepielski AM, Hung KL, Bein EEB \& McPeek MA. 2010. Experimental evidence for neutral community dynamics governing an insect assemblage. Ecology 91: $847-857$.

Stevens PF. 2001 onwards. Angiosperm Phylogeny Website. Version 14, July 2017 [and more or less continuously updated since]. [WWW document] URL http://www.mobot.org/MOBOT/research/APweb/welcome.html [accessed 13 June 2017]

Strauss SY. 1997. Floral characters link herbivores, pollinators, and plant fitness. Ecology 78: 1640-1645.

Strauss SY, Rudgers JA, Lau JA \& Irwin RE. 2002. Direct and ecological costs of resistance to herbivory. Trends in Ecology and Evolution 17: 278-285.

This article is protected by copyright. All rights reserved 
Strauss SY \& Whittall JB. 2006. Non-pollinator agents of selection on floral traits. Ecology and evolution of flowers (eds. L.D. Harder \& S.C.H. Barrett), chap. 7, pp. 120-138. Oxford, UK: Oxford University Press, 1st edn.

Theis N. 2006. Fragrance of Canada thistle (Cirsium arvense) attracts both floral herbivores and pollinators. Journal of Chemical Ecology 32: 917-927.

Vamosi JC, Moray CM, Garcha NK, Chamberlain SA \& Mooers AØ. 2014. Pollinators visit related plant species across 29 plant-pollinator networks. Ecology and Evolution 4: 2303-2315.

\section{Volf M, Pyszko P, Abe T, Libra M, Kotásková N, Šigut M, Kumar R,} Kaman O, Butterill PT, Šipoš J, Abe H, Fukushima H, Drozd P, Kamata N, Murakami M \& Novotny V. 2017. Phylogenetic composition of host plant communities drives plant-herbivore food web structure. Journal of Animal Ecology 86: $556=565$.

Waser NM, Chittka L, Price MV, Williams NM \& Ollerton J. 1996. Generalization in pollination systems, and why it matters. Ecology 77: 1043-1060.

Wilson P, Wolfe AD, Armbruster WS \& Thomson JD. 2007. Constrained lability in floral evolution: counting convergent origins of hummingbird pollination in Penstemon and Keckiella. New Phytologist 176: 883-890.

Wise MJ \& Rausher MD. 2013. Evolution of resistance to a multiple-herbivore community: genetic correlations, diffuse coevolution, and constraints on the plant's response to selection. Evolution 67: 1767-1779.

\section{Yguel B, Bailey R, Tosh ND, Vialatte A, Vasseur C, Vitrac X, Jean F \&}

This article is protected by copyright. All rights reserved 
Prinzing A. 2011. Phytophagy on phylogenetically isolated trees: Why hosts should escape their relatives. Ecology Letters 14: 1117-1124.

Yguel B, Bailey RI, Villemant C, Brault A, Jactel H \& Prinzing A. 2014.

Inseet herbivores should follow plants escaping their relatives. Oecologia $\mathbf{1 7 6}$ :

$521-532$.

Zanne AE, Tank DC, Cornwell WK, Eastman JM, Smith SA, FitzJohn RG, McGlinn DJ, O'Meara BC, Moles AT, Reich PB, Royer DL, Soltis DE, Stevens PF, Westoby M, Wright IJ, Aarssen L, Bertin RI, Calaminus A, Govaerts R, Hemmings F, Leishman MR, Oleksyn J, Soltis PS, Swenson

NG, Warman L \& Beaulieu JM. 2014. Three keys to the radiation of angiosperms into freezing environments. Nature 506: 89-92.

This article is protected by copyright. All rights reserved 


\section{Notes legends}

Notes 1: Sources for networks. Original sources for all networks used in this study.

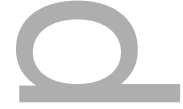

Notes 2: R implementation of tuple-form regression. Further details and $\mathrm{R}$ code for our statistical model.

Notes 3: Repeating our analyses with proportion of shared partners. Results when niche overlap is defined as the proportion of shared interaction partners rather than by a tuple of shared and unshared partners.

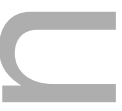

Notes 4: A test of connectance. Methods and results for a test as to whether the connectance of a network affects the relationship between phylogenetic distance and niche overlap.

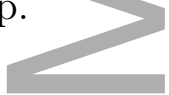

Notes 5: Distributions of $p$-values for permuted networks. Figures showing the distributions of $p$-values in permuted networks referenced in Figs. 1-2.

Notes 6: Details of within-family regressions. Supplemental results for within-family regressions, including a comparison of $p$-values and critical values for the sequential correlated Bonferroni test. 


\section{Tables}

Table 1: Change $(\Delta)$ in log odds (per million years of phylogenetic distance) of a pair of plants in the same family sharing a pollinator.

\begin{tabular}{|lrr||lrr|}
\hline Family & $\Delta$ log odds & $P$-value & Family & $\Delta$ log odds & $P$-value \\
\hline Adoxaceae & -65.8 & 0.163 & Malvaceae & -5.56 & 0.363 \\
Amaryllidaceae & -17.9 & $\mathbf{0 . 0 1 5}$ & Melastomataceae* & 5.19 & 0.577 \\
Apiaceae & 10.9 & $\mathbf{0 . 0 0 6}$ & Montiaceae & -1.12 & 0.87 \\
Apocynaceae & -6.96 & $\mathbf{0 . 0 3 7}$ & Myrtaceae & 8.55 & 0.071 \\
Asparagaceae & -6.23 & 0.189 & Oleaceae & 0.995 & 0.855 \\
Asteraceae* & -1.47 & $<\mathbf{0 . 0 0 1}$ & Onagraceae & -556 & $>0.999$ \\
Berberidaceae & $-1.48 \times 10^{3}$ & $>0.999$ & Orchidaceae & -14.5 & 0.145 \\
Boraginaceae & -5.15 & $<\mathbf{0 . 0 0 1}$ & Orobanchaceae & 24.2 & 0.326 \\
Brassicaceae & -11.2 & 0.072 & Papaveraceae & -11.2 & 0.511 \\
Calceolariaceae & 156 & 0.998 & Phyllanthaceae & 9.99 & 0.433 \\
Campanulaceae & 334 & 0.999 & Plantaginaceae & -8.48 & $\mathbf{0 . 0 0 1}$ \\
Caprifoliaceae & 0.31 & 0.959 & Poaceae* & 69.2 & $\mathbf{0 . 0 0 3}$ \\
Caryophyllaceae & 2.09 & 0.644 & Polygonaceae & -14.8 & $<\mathbf{0 . 0 0 1}$ \\
Cistaceae & -11.4 & $<\mathbf{0 . 0 0 1}$ & Primulaceae & 14.9 & 0.343 \\
Convolvulaceae & -1.84 & 0.837 & Ranunculaceae & -38 & $<\mathbf{0 . 0 0 1}$ \\
Ericaceae & 4.61 & 0.116 & Rosaceae & 0.759 & 0.735 \\
Fabaceae* & -12.9 & $<\mathbf{0 . 0 0 1}$ & Rubiaceae* & -13 & $\mathbf{0 . 0 2 6}$ \\
Geraniaceae & -3.31 & 0.624 & Salicaceae & -1.9 & 0.545 \\
Hydrangeaceae & 0.057 & 0.982 & Sapindaceae & 821 & 0.999 \\
Iridaceae & -27.9 & 0.078 & Saxifragaceae & -0.092 & 0.992 \\
Lamiaceae & -5.01 & $<\mathbf{0 . 0 0 1}$ & Solanaceae & -21.9 & 0.189 \\
Lauraceae & -79.9 & $<\mathbf{0 . 0 0 1}$ & Tropaeolaceae & 192 & 0.997 \\
Loasaceae & -865 & $>0.999$ & Verbenaceae & -9.03 & 0.627 \\
Malpighiaceae & 2.8 & 0.168 & Violaceae & -0.487 & 0.974 \\
\hline
\end{tabular}

We were able to fit these models to 48 plant families (see Materials and Methods for details). Families marked with an asterisk were also sufficiently diverse to model in herbivory networks. Statistically significant values are indicated in bold.

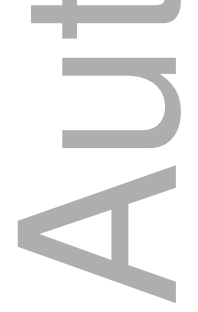


Table 2: Change $(\Delta)$ in log odds (per million years of phylogenetic distance) of a pair of plants in the same family sharing a herbivore.

\begin{tabular}{|lrr|}
\hline Family & $\Delta$ log odds & $P$-value \\
\hline Asteraceae & -1.73 & 0.550 \\
Euphorbiaceae & -19.2 & $<\mathbf{0 . 0 0 1}$ \\
Fabaceae & 18.7 & $\mathbf{0 . 0 4 6}$ \\
Melastomataceae & -13.2 & $\mathbf{0 . 0 2 2}$ \\
Moraceae & -2.13 & 0.092 \\
Nothofagaceae & -595 & $>0.999$ \\
Pinaceae & -25.8 & 0.733 \\
Poaceae & -4.50 & $\mathbf{0 . 0 2 0}$ \\
Rubiaceae & -8.16 & $\mathbf{0 . 0 0 6}$ \\
\hline
\end{tabular}

Nine plant families were sufficiently diverse in our dataset to permit this analysis (see Materials and Methods for details). For each pattern of overlap, we show the change in log odds per million years and the associated $P$-value. Statistically significant values are indicated in bold.

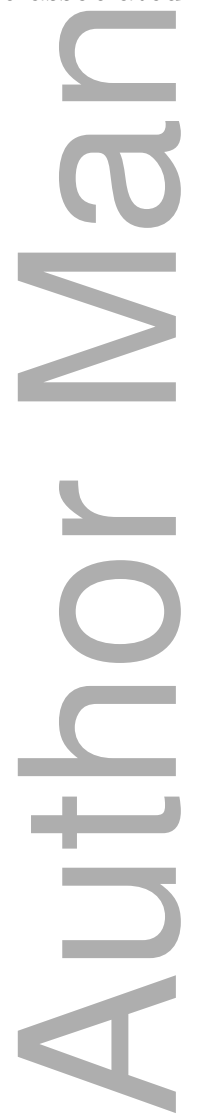




\section{Figures}
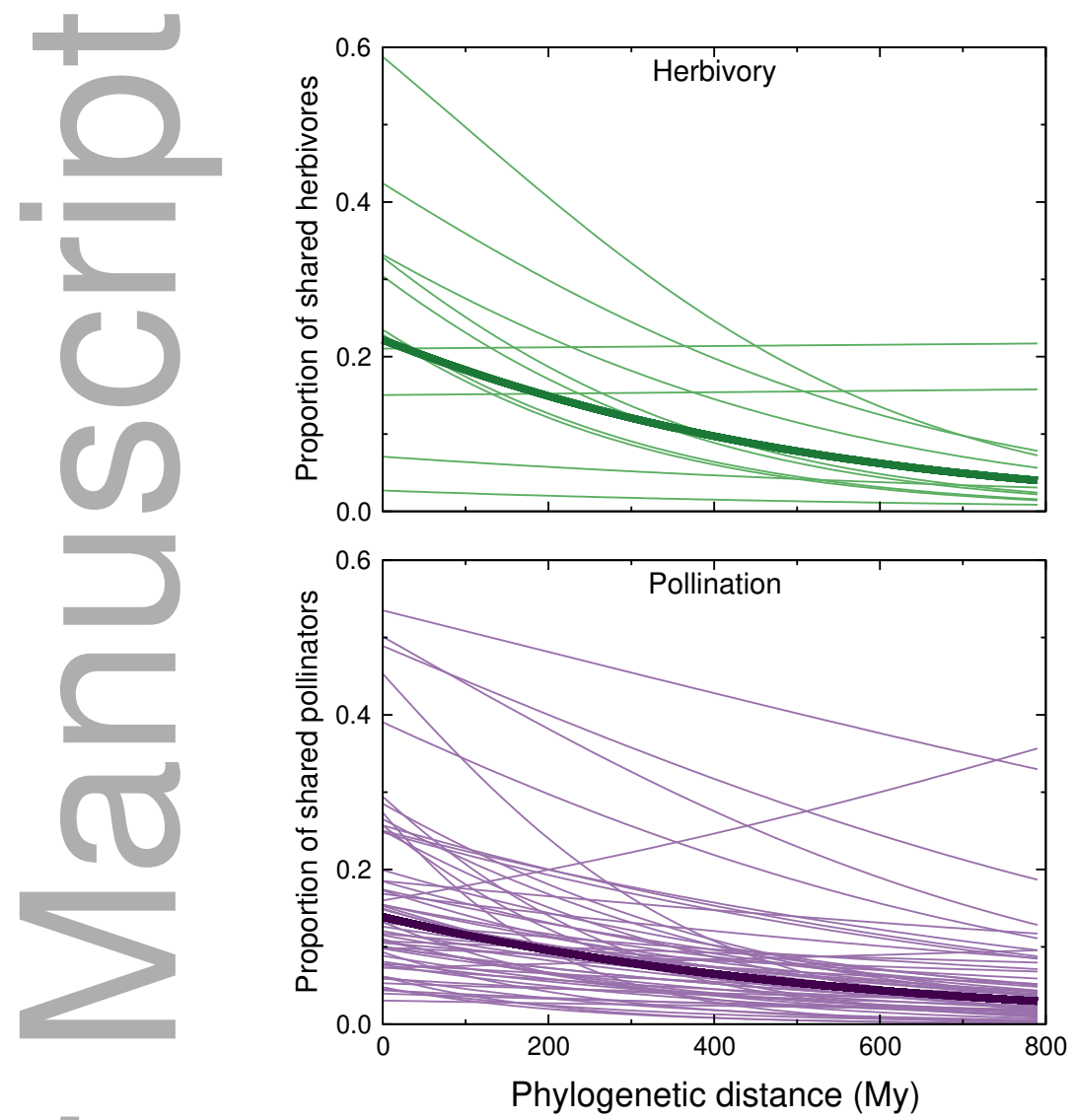

Figure 1: Results of a mixed-effects logistic regression of pairwise niche overlap against phylogenetic distance for plants in 11 herbivory networks (top; green) and 59 pollination networks (bottom; purple). In both network types, the probability of a pair of plants sharing an interaction partner decreased with increasing phylogenetic distance (thick, dark lines). There was substantial variation among networks (thin, pale lines) of both types. The slope of the regression for each network was significantly more extreme than that obtained from 999 permutatations of that network (slopes obtained from the permuted networks ranged between $-1.34 \times 10^{-12}$ and $\left.9.19 \times 10^{-13}\right)$. 

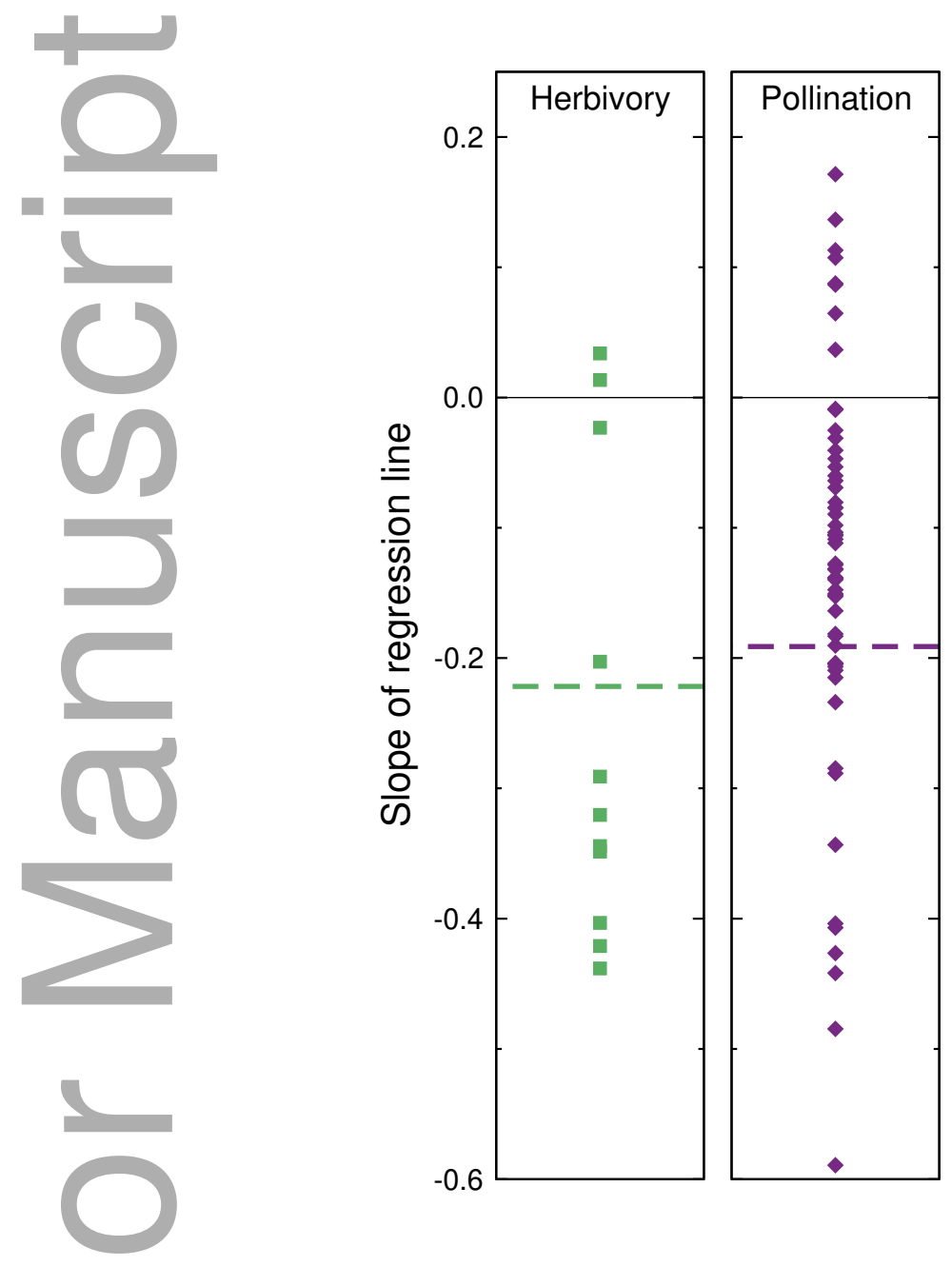

Figure 2: The slopes of the mixed-effect logistic regression of pairwise niche overlap against phylogenetic distance (representing the change in log odds of a pair of plants sharing an interaction partner) was significantly different from 0 for each network. Here we show the observed slopes for herbivory (green squares) and pollination (purple diamonds) networks. Thiek, dashed lines represent the mean slopes across all networks of each type. The maximum and minimum slopes obtained from 999 permutations of each network are depicted by thin, black lines. For both network types, the slopes obtained from permuted networks were always very close to 0 (range $-1.34 \times 10^{-12}$ to $9.19 \times 10^{-13}$ ). 


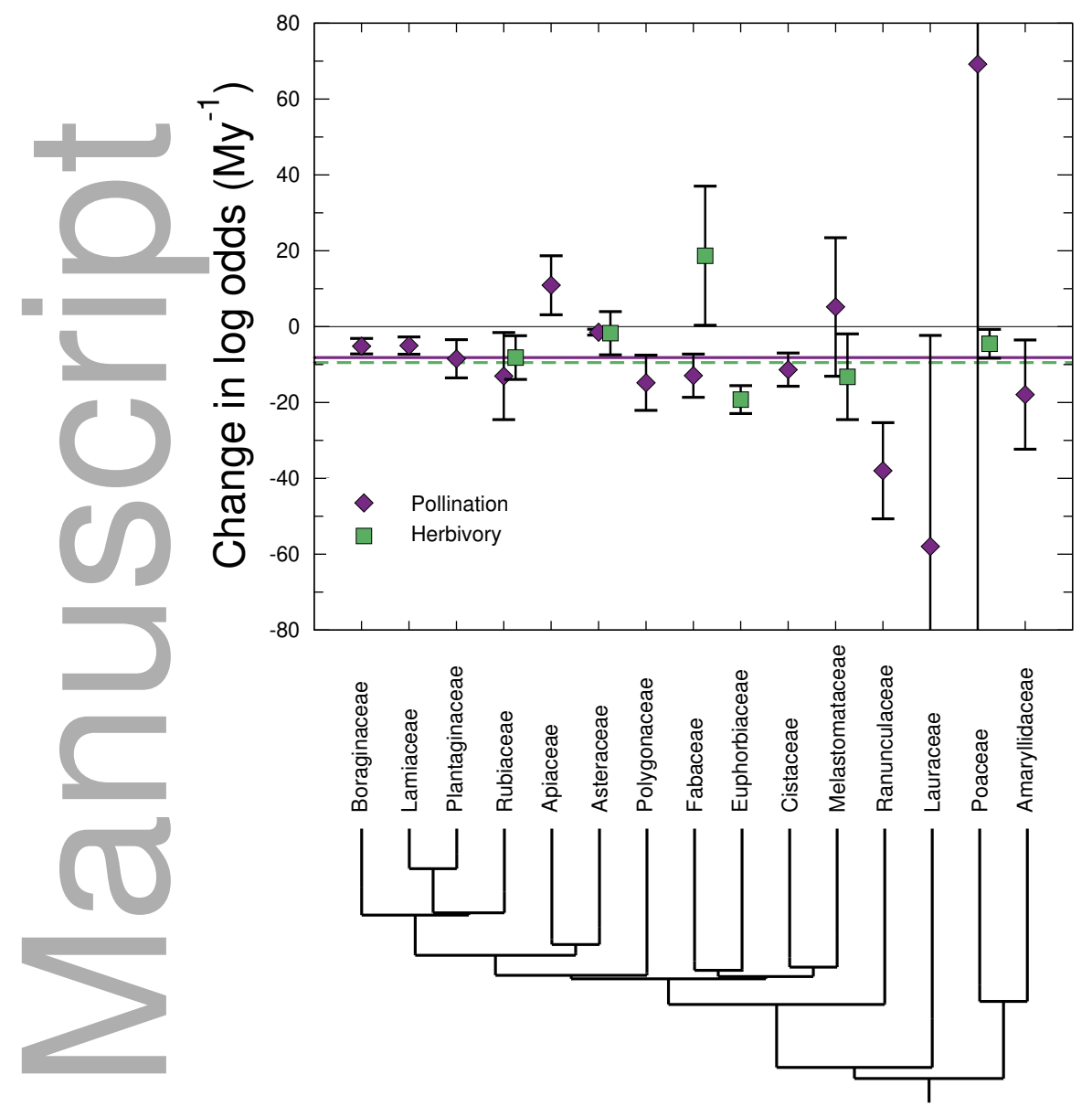

Figure 3: Change in the log odds of a pair of plants sharing a pollinator or herbivore (i.e., the slopes of the mixed-effect logistic regressions) as phylogenetic distance between the plants increases. These values are analogous to the slopes of the regression lines from Eq. 2-3 and represent the change in the probability of observing shared interaction partners per million years of divergence time. For clarity, we show only the 15 plant families for which the slope of the regression of the proportion of shared interaction partners against phylogenetic distance was significant in at least one network type. Note that the change in log odds for Asteraceae in herbivory networks and Melastomataceae in pollination networks are not significantly different from zero; we present these values only for comparison across network types. All other plant families were well-represented in only one network type. Families in pollination networks are indicated by dark purple diamonds while families in herbivory networks are indicated by pale green circles. We also show the slope of the relationship between the log-odds of observing each overlap pattern and phylogenetic distance across all plant families in herbivory (pale, green horizontal line) and pollination (dark, purple horizontal line) networks. The phylogenetic tree below the plots indicates the relatedness between these plant families. Error bars represent $95 \%$ confidence intervals. 


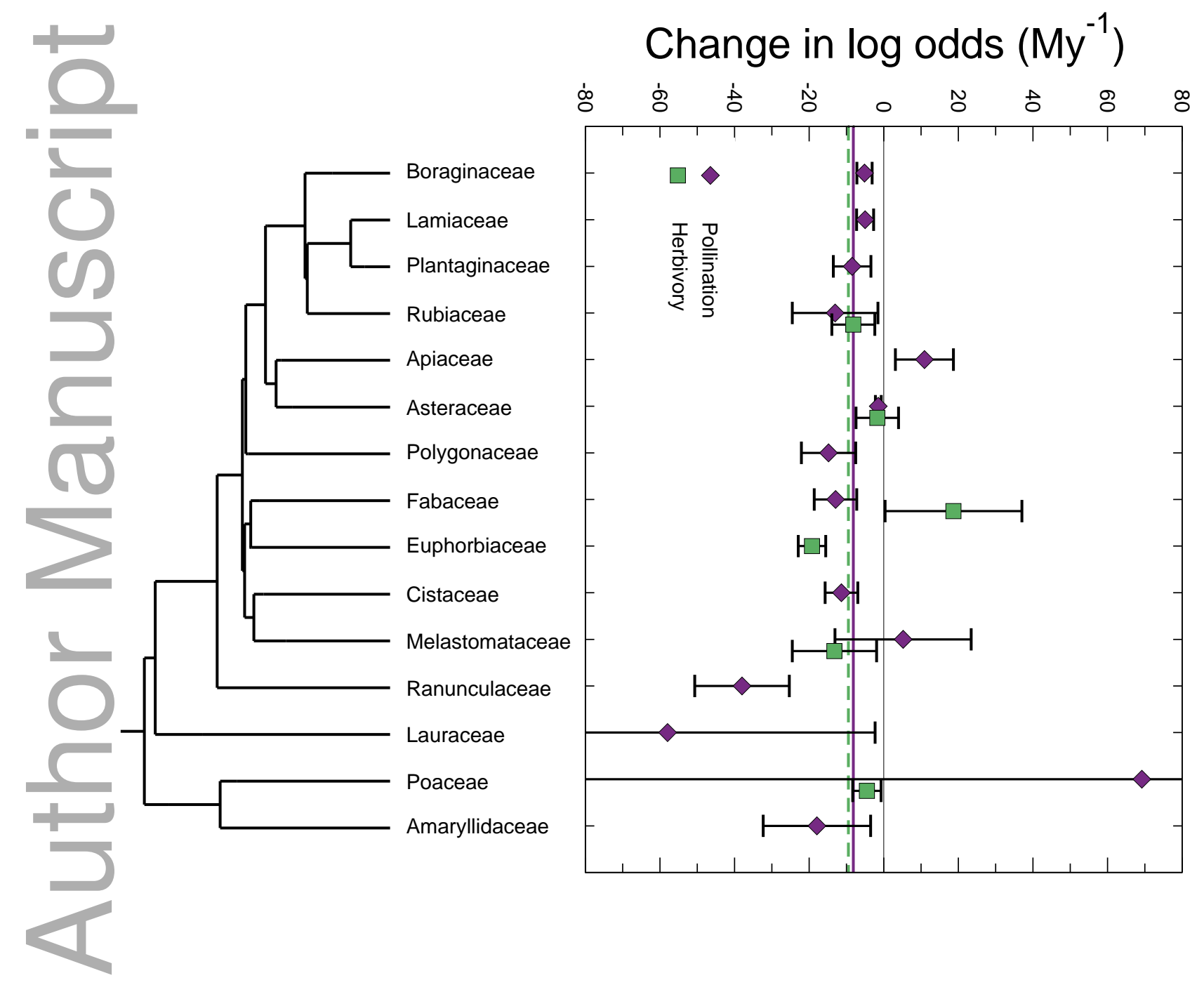

This article is protected by copyright. All rights reserved 


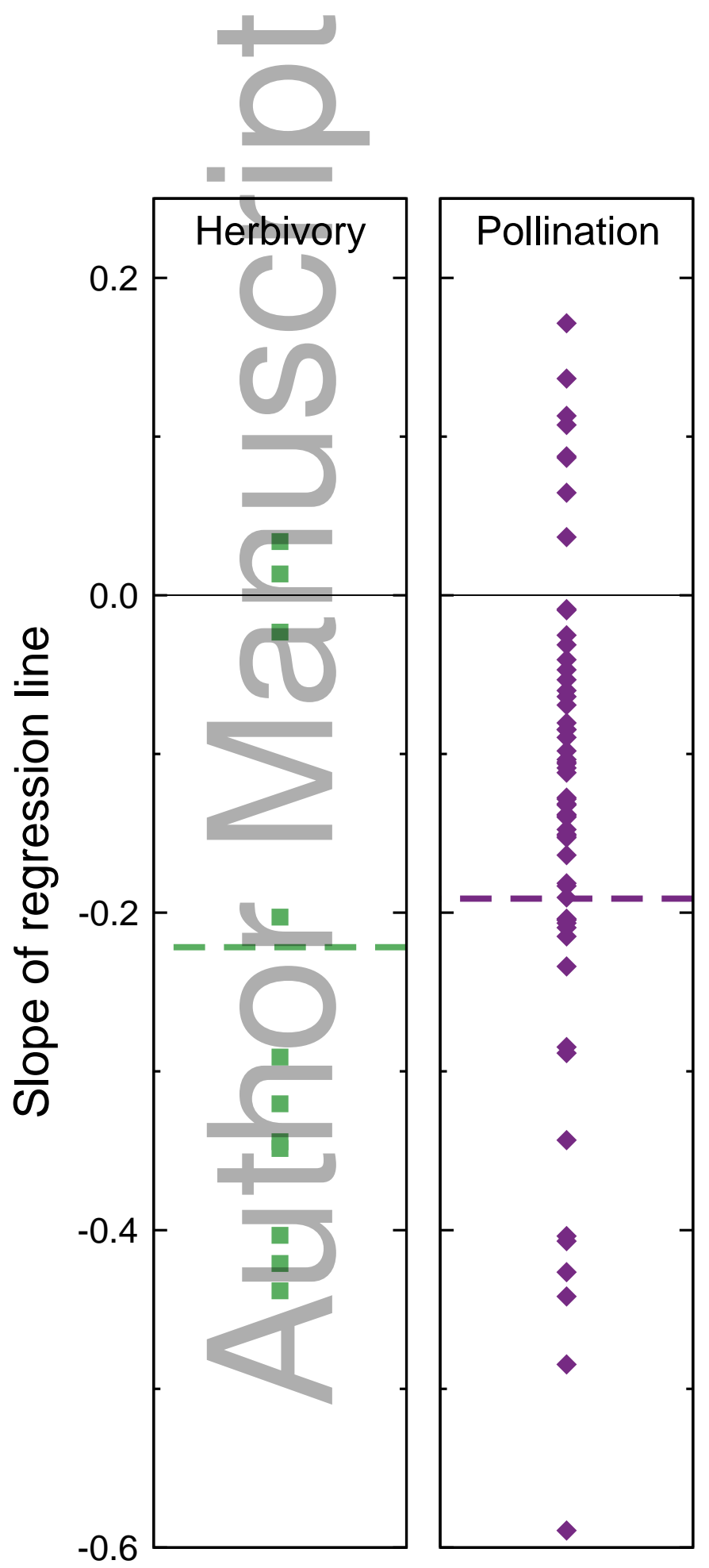

This article is protected by copyright. All rights reserved 

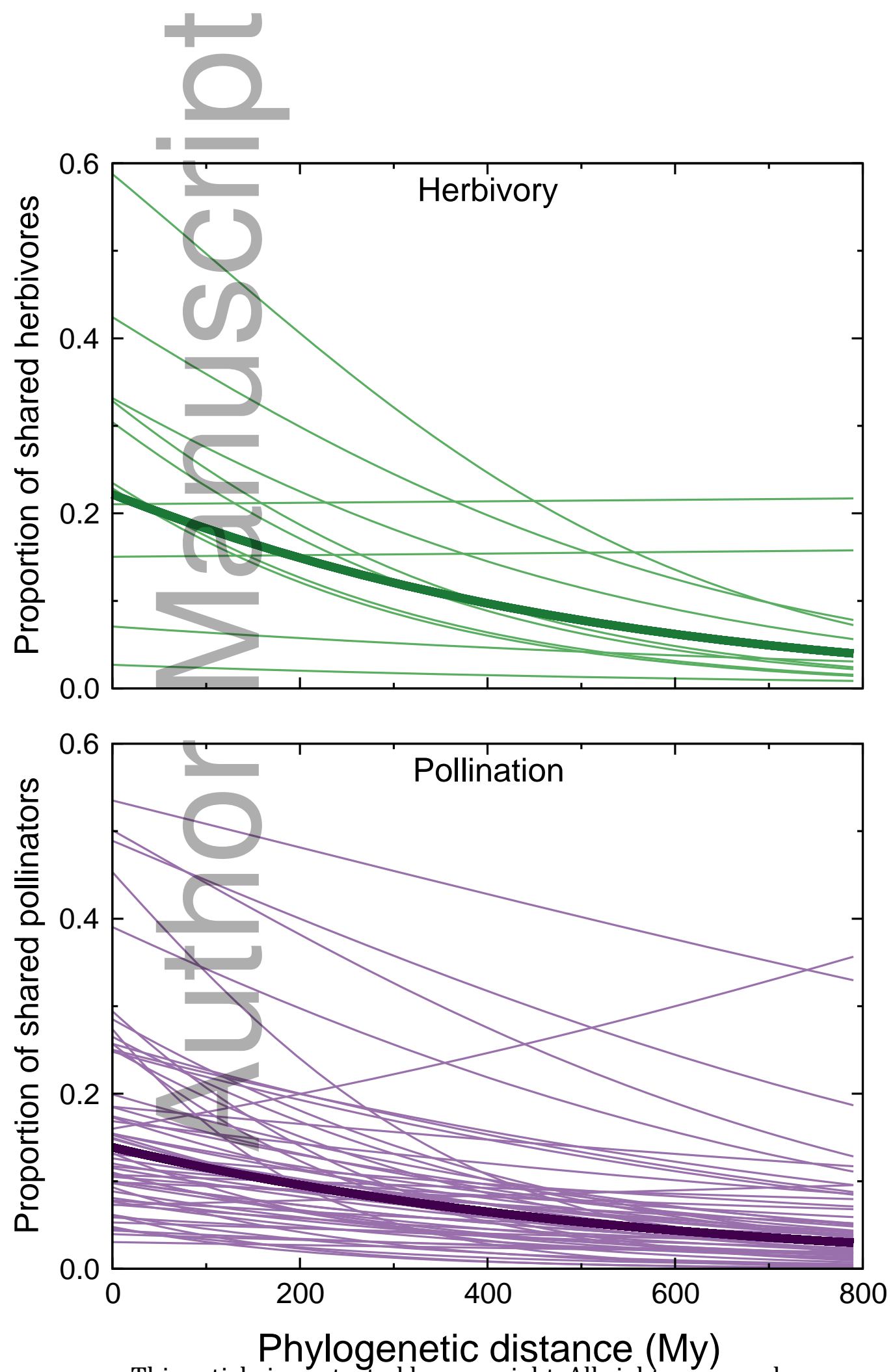

This article is protected by copyright. All rights reserved 


\section{University Library}

\section{- M I I N E R VA \\ A gateway to Melbourne's research publications}

Minerva Access is the Institutional Repository of The University of Melbourne

Author/s:

Cirtwill, AR;Dalla Riva, GV;Baker, NJ;Ohlsson, M;Norstrom, I;Wohlfarth, I-M;Thia, JA;Stouffer, DB

Title:

Related plants tend to share pollinators and herbivores, but strength of phylogenetic signal varies among plant families

Date:

2020-05

Citation:

Cirtwill, A. R., Dalla Riva, G. V., Baker, N. J., Ohlsson, M., Norstrom, I., Wohlfarth, I. -M., Thia, J. A. \& Stouffer, D. B. (2020). Related plants tend to share pollinators and herbivores, but strength of phylogenetic signal varies among plant families. NEW PHYTOLOGIST, 226 (3), pp.909-920. https://doi.org/10.1111/nph.16420.

Persistent Link:

http://hdl.handle.net/11343/275416 